
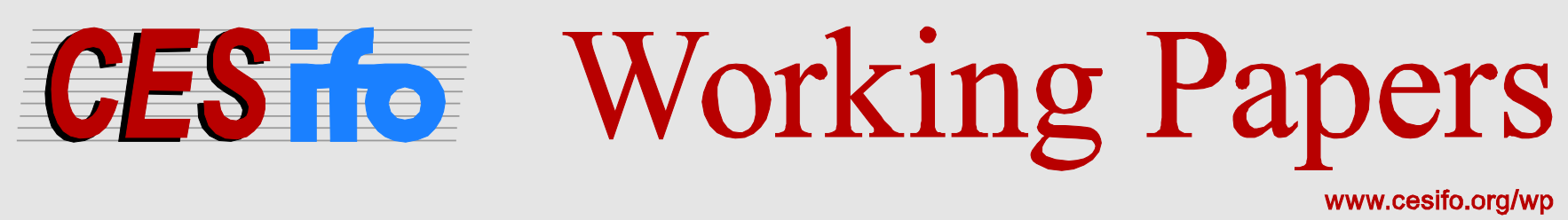

\title{
Location of Foreign Direct Investment in Vertically Related Markets
}

\author{
Chrysovalantou Milliou
}

\author{
CESIFO WORKING PAPER NO. 4117 \\ CATEGORY 11: INDUSTRIAL ORGANISATION \\ FEBRUARY 2013
}
An electronic version of the paper may be downloaded
- from the SSRN website: Www.SSRN.com
- from the RePEc website: Www.RePEc.org
- from the CESifo website: www.CESifo-group.org/wp

\section{CESifo}




\title{
Location of Foreign Direct Investment in Vertically Related Markets
}

\begin{abstract}
We provide an alternative explanation for the commonly observed FDI in developed countries (DCs) considering a vertically related market structure and endogenizing vertical technology transfer (VTT). We show that even though VTT is more costly in a less developed country (LDC), a multinational does not always transfer less technology there than in a DC. Moreover, we show that a multinational sometimes locates its FDI in a DC where, although downstream competition is stronger than in a LDC, it can obtain the input at better terms due to VTT. Independently of whether the host country is more or less developed, FDI is always welfare-enhancing.
\end{abstract}

JEL-Code: L130, F120, F230.

Keywords: foreign direct investment, host country, vertical relations, developed countries.

\author{
Chrysovalantou Milliou \\ Department of International and \\ European Economic Studies \\ Athens University of Economics and Business \\ Greece - Athens 10434 \\ cmilliou@aueb.gr
}

January 2013

This research has been co-financed by the European Union (European Social Fund .ESF) and Greek national funds through the Operational Program "Education and Lifelong Learning” of the National Strategic Reference Framework (NSRF) - Research Funding Program: Thalis Athens University of Economics and Business - "New Methods in the Analysis of Market Competition: Oligopoly, Networks and Regulation”. Full responsibility for all the shortcomings is mine. 


\section{Introduction}

Developed countries (DCs) have been steadily the main origin of Foreign Direct Investment (FDI). ${ }^{1}$ The destination, though, of FDI has varied significantly during the years. Initially, FDI was mostly directed towards less developed countries (LDCs). However, eventually the DCs became the main destination of FDI, with the percentage of FDI located in DCs exceeding 70\% in 2007 and 2008 (UNCTAD, 2007, 2008).

The prominent explanation that the literature has provided for the location of FDI in LDCs is that the entering Multinational Enterprises (MNEs) enjoy a competitive advantage relative to the LDCs' domestic firms. As a result, the MNEs face weak competition in LDCs and earn high profits. One of the explanations that the literature has provided for the location, instead, of FDI in DCs (see e.g., Motta and Ronde, 1999, Bjorvatn and Erckel, 2006) is that the MNEs invest in DCs in order to gain access to technological resources and advances. Other explanations argue that the MNEs invest in DCs because they enjoy more their competitive advantages there due to the better protection of the intellectual property rights (see e.g., Fumagalli, 2003) or because the market size in the DCs is larger (see e.g., Barros and Cabral, 2000, Ma, 2011).

In this paper, we study a MNE's decision regarding the location of its FDI: Will it invest in a DC or in a LDC? We address this issue by considering a vertically related market instead of a one-tier market, and by endogenizing the technology transferred by the MNE to the domestic suppliers. In particular, we take into account the fact that most real world markets are vertically related. That is, they consist of final product manufacturers downstream firms - which manufacture their products using intermediate goods that they obtain from firms operating at previous stages of the production chain - upstream firms. We also take into account that, as extensive empirical evidence indicates, multinationals are often involved in vertical technology transfer (VTT), i.e., they deliberately transfer technology to their local suppliers (see e.g., Pack and Saggi, 2001, Javorcik, 2004).

In our model, a MNE from a DC, is deciding whether it will enter into a DC or a LDC through the establishment of a new production plant. Upon entry into a host country,

\footnotetext{
${ }^{1}$ According to OECD (2002) "More than $90 \%$ of the initiators of the [FDI] outflows, were located in developed countries.", p.7.
} 
the MNE competes with a domestic downstream firm and sources an input from a local upstream monopolist to which it transfers technology and lowers its production cost. The host countries differ in two respects. First, the LDC's domestic downstream firm faces a cost-disadvantage relative to the DCs' domestic downstream firm. And second, VTT is more costly in the LDC than in the DC, i.e., the MNE has to pay more in order to train the upstream supplier in the LDC due, for instance, to the fact that its employees are less familiar with advanced technologies and methods than the respective employees of the DC's domestic upstream firm. The MNE chooses the level of VTT in its host country. In turn, the host country's domestic upstream firm sets the wholesale prices for the input, and the downstream firms compete in quantities.

Surprisingly, we demonstrate that even though VTT is more costly in the LDC, the MNE does not always transfer less technology when it locates there than when it locates in the DC. When both the efficiency of its domestic downstream firm and the cost of VTT are low enough in the LDC, more VTT takes place there. As expected, the cost of VTT affects negatively the technology transfer in the LDC. However, the LDC's domestic downstream firm's cost disadvantage reinforces the incentives for VTT. This occurs because higher VTT results into lower wholesale prices, and thus, into lower marginal cost faced by the downstream firms. As the inefficiency of the LDC's domestic downstream firm gets more severe, the MNE's market share in the LDC increases. As a consequence, the MNE benefits then more from a decrease in its marginal cost caused by more VTT.

In a one-tier industry, a MNE always prefers to locate its FDI in the LDC since it faces weaker competition there than in the DC. In contrast, in a vertically related industry, the MNE prefers to locate its FDI in the DC as long as the technological gap among the two countries is sufficiently small. Why is that? In a vertically related industry, the MNE's location decision is affected by the market conditions in both the upstream and downstream market. Due to the weaker downstream competition in the LDC, the downstream market conditions are always in favor of locating in the LDC. However, the upstream market conditions are not always in favor of locating in the LDC. This is so because, as explained above, when the LDC's downstream firm's cost disadvantage is not sufficiently large and/or VTT is too costly in the LDC, the MNE enjoys higher upstream 
production efficiency, and in turn, obtains the input at better terms if it locates in the DC. This finding points out that the consideration of the vertical structure of the market allows us to provide a novel explanation for the commonly observed FDI in DCs.

Which are the implications of FDI for its host country? Under FDI, a domestic downstream firm pays a lower wholesale price, but at the same time its market share declines due to the increased competition from the entering MNE. The second effect dominates and the domestic downstream firm is worse off. The opposite is true for the domestic upstream firm since, under FDI, first, its efficiency is enhanced as a result of VTT, and second, it faces more demand due to the increase in backward linkages. The intensification in the host country's downstream competition, under FDI, as well as the increase in its downstream efficiency explain, in turn, the positive impact of FDI on its host country's consumers' surplus and total welfare. On the basis of this, we can conclude that in cases where there is potential for MNE to source supplies from domestic suppliers, the host countries, independently of whether they are more or less developed, should encourage FDI.

Considering what happens when the domestic downstream firm cannot free-ride on VTT, we note that FDI would lead then to more VTT than in the presence of free-riding. More VTT would also take place in the LDC if the local upstream supplier was not allowed to price discriminate among the foreign and the domestic downstream firms. Our main findings are robust to these two extensions of our model, but also to alternative ways of modeling VTT, the differences among the host countries and vertical contracting.

Traditionally, the literature on FDI with strategic interactions focuses on one-tier industries. Recently though, a number of papers on FDI by Pack and Saggi (2001), Goh (2005), Lin and Saggi (2007, 2011), Blasvik (2010), and Carluccio and Fally (2011) consider a vertical market structure. ${ }^{2,3}$ Lin and Saggi (2011) analyze the incentives for upstream and downstream FDI by two separate firms and their host country effects. They show that there is a coordination problem in their entry decisions. Since, though, entry by both

\footnotetext{
${ }^{2}$ There is another branch of the literature which studies exports in vertically related markets, but does not consider FDI, see e.g., Ishikawa and Spencer (1999), and Chou (2011).

${ }^{3}$ Rodriguez-Clare (1996) and Markusen and Venables (1999) also study FDI in a two-tier industry, but they consider a setting with monopolistic competition; hence, they abstact from strategic interactions among foreign investors that are central to the literature with oligopolistic markets.
} 
firms is the best case scenario for the host country, they argue that an FDI subsidy at one level may be sufficient to incur entry at both levels. Carluccio and Fally (2011) examine the extent of technology adoption in the host country, in a setting where there is initially incompatibility between the foreign and the domestic technologies, and upon foreign entry in the downstream sector, the domestic upstream suppliers decide whether to adopt the foreign technology and produce compatible inputs for the MNEs or not.

The empirical literature on technology transfer through vertical linkages between MNEs and domestic suppliers is vast. It includes, among others, the studies on LDCs, Lithuania, Spain, Indonesia, and Canada respectively by Lall (1980), Javorcik (2004), Jabbour and Mucchielli (2007), and Blalock and Gertler (2008, 2009) and Lileeva (2010). These studies provide strong evidence on the presence of VTT and find that backward linkages with foreign affiliates sharply increase the productivity of domestic suppliers. In line with the empirical evidence and with us, Pack and Saggi (2001), Goh (2005), Lin and Saggi (2007) and Blasvik (2010) allow for VTT under FDI. In particular, Pack and Saggi (2001) examine how downstream FDI and VTT in the presence of spillovers among the domestic upstream firms can lead to both upstream and downstream entry. Building on their model, Goh (2005) and Balsvik (2010) endogenize the level of VTT. The former paper endogenizes the technological efforts of the local upstream firms, and the latter the MNE's mode of entry. Finally, Lin and Saggi (2007) consider the effects of downstream FDI on its host country, when the MNE might impose an exclusivity condition on local suppliers in return from transferring technology to them. In all of the above mentioned papers, there is only one potential host country. Hence, in contrast to us, these papers do not examine how the characteristics of the different host countries influence VTT, and more importantly, they do not deal with the issue of the location choice of FDI. An exception is a recent paper by Ma (2011), who, in line with us, examines a MNE's choice among two potential host countries for its FDI, within a vertically related industry. In his setting though VTT is not present and the host countries differ in terms of their market size and the possibility of local input sourcing, and not in terms of their efficiency.

The rest of the paper is organized as follows. Section 2 includes our main model and the analysis of the benchmark case of a one-tier industry. Section 3 derives the market 
equilibrium in the FDI's host country and analyzes the MNE's location decision and its impact on its host country. Section 4 contains various extensions of our main model. Finally, Section 5 concludes. All the proofs are relegated to the Appendix.

\section{The Model}

There are two potential host countries at which an MNE is considering expanding though FDI. One is a developed country (DC) and the other one is a less developed country (LDC). In each host country $i$, with $i=D C, L D C$, there is initially a domestic downstream firm, denoted by $D_{i}$, which produces a final product using, in a one-to-one proportion, an input which it obtains from a domestic upstream monopolist, denoted by $U_{i}$.

The marginal production cost faced by each $D_{i}$ equals the sum of the wholesale price, $w_{i}$, that $U_{i}$ charges to $D_{i}$ per unit of input, and an exogenous marginal cost, $d_{i} \cdot{ }^{4} \mathrm{We}$ assume that the DC's domestic downstream firm employs a more efficient production technology than the LDC's domestic downstream firm. In particular, we assume that $d_{L D C}>d_{D C}=0$.

The MNE undertakes Greenfield Investment to one of the host countries, i.e., it establishes a new production plant there. The MNE's subsidiary in host country $i$, denoted by $D_{F i}$, produces the same (homogeneous) final good as the domestic downstream firm $D_{i}$ obtaining the input from the domestic upstream firm $U_{i} \cdot{ }^{5} D_{F i}$ 's marginal production cost is $d_{F}+w_{F i}$, where $w_{F i}$ is the wholesale price that $U_{i}$ charges to $D_{F i}$ and $d_{F}=d_{D C}=0$. This implies that the domestic upstream firm can price discriminate among the domestic and the foreign downstream firms. ${ }^{6}$ It also implies that the MNE originates from a DC since its subsidiary is as efficient as the developed host country's domestic downstream firm. It follows that $d_{L D C}$ is a measure of the LDC's domestic downstream firm's costdisadvantage relative to the MNE's subsidiary.

\footnotetext{
${ }^{4}$ In Section 4, we discuss what would happen if trading was conducted through non-linear two-part tariff contracts instead of through linear wholesale price contracts.

${ }^{5}$ As Lin and Saggi (2007) point out, local sourcing might arise because of technological reasons, such as high transportation costs, or because of policy restrictions, such as local content requirements imposed by the host country's government.

${ }^{6}$ In Section 4, we discuss what would happen if price discrimination was not allowed.
} 
$U_{i}$ 's marginal cost depends on whether or not the MNE invests in its country. More specifically, when the MNE undertakes FDI in host country $j$, with $i, j=L D C, D C$ and $i \neq j, U_{i}$ 's marginal cost is $u$, where $u$, with $u>0$, is an exogenous production cost. Instead, when the MNE undertakes FDI in host country $i, U_{i}$ 's marginal cost is $u-t_{i}$, where $t_{i}$ is the extent of VTT from $D_{F i}$ to $U_{i}$, with $0 \leq t_{i} \leq u$. In other words, we assume that when the MNE enters into a country, it can transfer technology to the local input supplier so that the latter becomes more efficient. ${ }^{7}$ This could happen, for instance, by offering training to the employees of the upstream supplier. ${ }^{8}$ The cost of technology transfer faced by $D_{F i}$ is characterized by diminishing returns to scale and it is given by $\mu_{i} t_{i}^{2} / 2$. We assume that $\mu_{D C}=1$ and $\mu_{L D C}=\mu$ with $\mu>1$, i.e., technology transfer is more costly in the LDC. This could be the case because $U_{L D C}$ 's employees are less educated than $U_{D C}$ 's employees, and thus, training requires more effort and time in the LDC. Alternatively, it could be the case because the upstream technology used in the LDC country differs from the one used in the DC country, and as a consequence, explaining the technological information to the upstream supplier is more demanding in the LDC.

Each downstream firm sells its final product only in the domestic market in which it has a production plant..$^{9}$ Demand for the final product in each host country $i$ is given by $p_{i}\left(Q_{i}\right)=a-Q_{i}$, where $Q_{i}$ is the total quantity produced in country $i$ and $a$ is a measure of the market size with $a>\operatorname{Max}\left\{u, d_{L D C}\right\}$.

\footnotetext{
${ }^{7}$ Alternatively, VTT could lead to the improvement of the input's quality, and subsequently, to the increase in the final product's quality. We analyze this possibility in Section 4.

${ }^{8}$ As argued by Jabbour and Mucchielli (2007), case studies indicate that foreign firms often help their local suppliers to upgrade their production process through the training of workers, visits to the supplier's plant by the foreign firm's technical staff and the provision of blueprint and information on the production techniques. Similarly, Lall (1980), in his empirical study of VTT in the Indian trucking industry, notes that a MNE might help prospective suppliers set up production capacities; it might provide technical assistance to raise the quality of suppliers' products and/or to facilitate their innovations; or it might provide training and help in management and organization. In the same spirit, in the electronics sector of Malaysia, Moran (2001) observes that foreign investors assigned technicians to their local suppliers' plants to help set up and supervise automated production and testing procedures, assisting them to keep pace with modern technologies.

${ }^{9}$ We assume that local presence is essential and rule out other ways of serving the foreign market such as exports. This could be the case, for instance, because the downstream firms are active in the services industry where firms can provide their services only in the markets in which they are located (see Kurata et al., 2011). This could also be the case because the tariffs that the host countries impose on imports or the transportation costs are prohibitively high. In general, this assumption allows us to focus on the FDI's host county choice and not on the choice among FDI and exports which has been studied extensively in the FDI literature.
} 
We implicitly assume that the operational, organizational and set-up costs of establishing and running two foreign affiliates are prohibitively high, and thus, the MNE cannot invest in both host countries. ${ }^{10}$ For simplification reasons and without loss of generality, we abstain from including such costs in our analysis.

The sequence of moves is as follows. In stage one, the MNE decides whether it will undertake FDI in the DC or in the LDC. In stage two, the MNE decides how much technology it will transfer to the domestic upstream supplier of the country in which it has undertaken FDI. In stage three, if the MNE has undertaken FDI in host country $i, U_{i}$ chooses both $w_{i}$ and $w_{F i}$. Finally, in stage four, the MNE's subsidiary and the domestic downstream firm of its host country choose their quantities.

In order to guarantee that the domestic downstream firm(s) continue to be active in the market when FDI is undertaken in their home country, we need to assume that the LDC's domestic downstream firm is not too inefficient relative to the entering MNE. In particular, we assume the following throughout:

Assumption 1: $d_{L D C}<\widehat{d}_{L D C}(\mu) \equiv \frac{6 \mu(a-u)}{12 \mu-1}$.

We also need to assume that the initial upstream marginal cost is sufficiently high otherwise VTT can result into a negative upstream cost:

Assumption 2: $u>\left(a+d_{L D C}\right) / 18 \mu$.

As a benchmark, we first describe the market equilibrium when there is no upstream sector; hence, when the MNE operates in a one-tier industry, $t_{i}=w_{i}=w_{F i}=0$ by assumption. Upon entry in host country $i$, in the last stage, $D_{F i}$ and $D_{i}$ choose their outputs in order to maximize their respective profits:

$$
\begin{aligned}
& \underset{q_{F i}}{\operatorname{Max}} \pi_{D_{F i}}=\left(a-q_{F i}-q_{i}\right) q_{F i} ; \\
& \underset{q_{i}}{\operatorname{Max}} \pi_{D_{i}}=\left(a-q_{i}-q_{F i}\right) q_{i}-d_{i} q_{i} .
\end{aligned}
$$

The resulting equilibrium outputs and profits are:

$$
q_{F i}^{B}=\frac{a+d_{i}}{3} ; \quad q_{i}^{B}=\frac{a-2 d_{i}}{3} ; \quad \pi_{D_{F i}}^{B}=\frac{\left(a+d_{i}\right)^{2}}{9} ; \quad \pi_{D_{i}}^{B}=\frac{\left(a-2 d_{i}\right)^{2}}{9} .
$$

\footnotetext{
${ }^{10}$ For a similar assumption see e.g., Barros and Cabral (2000), Fumagalli (2003), Kurata et al. (2011).
} 
It is obvious that $\pi_{D_{F L D C}}^{B}-\pi_{D_{F D C}}^{B}=d_{L D C}\left(2 a+d_{L D C}\right)>0$. Therefore, when the MNE operates in a one-tier industry, it always locates its FDI in the LDC rather than in the DC. The intuition is straightforward: The MNE enjoys a cost advantage relative to the domestic firm only when it enters into the LDC. This, in turn, means that the MNE faces weaker competition in the LDC than in the DC. Since weaker competition translates into higher profits, the MNE chooses to locate its FDI in the LDC. Clearly, the larger is $D_{L D C}$ 's cost disadvantage $\left(d_{L D C}\right)$, the stronger are the MNE's incentives to invest in the LDC.

\section{Location and Impact of FDI}

In this Section, first, we obtain the market equilibrium in the host country in which the MNE locates its FDI, and then, we endogenize the FDI's location and examine its implications for its host country.

\subsection{FDI in Host Country $i$}

When the MNE invests in host country $i$, in the final stage, $D_{F_{i}}$ and $D_{i}$ choose their outputs in order to maximize their respective profits:

$$
\begin{aligned}
\underset{q_{F i}}{\operatorname{Max} \pi_{D_{F i}}} & =\left(a-q_{F i}-q_{i}\right) q_{F i}-w_{F i} q_{F i}-\mu_{i} t_{i}^{2} / 2 ; \\
\underset{q_{i}}{\operatorname{Max}} \pi_{D_{i}} & =\left(a-q_{i}-q_{F i}\right) q_{i}-\left(w_{i}+d_{i}\right) q_{i} .
\end{aligned}
$$

Solving (4) and (5), we obtain $q_{F i}\left(w_{F_{i}}, w_{i}\right)$ and $q_{i}\left(w_{F i}, w_{i}\right)$. In the previous stage, $U_{i}$ chooses the wholesale prices in order to maximize its own profits:

$$
\underset{w_{F i}, w_{i}}{\operatorname{Max}} \pi_{U_{i}}=w_{F i} q_{F i}\left(w_{F_{i}}, w_{i}\right)+w_{i} q_{i}\left(w_{F i}, w_{i}\right)-\left(u-t_{i}\right)\left[q_{F i}\left(w_{F i}, w_{i}\right)+q_{i}\left(w_{F i}, w_{i}\right)\right] .
$$

The resulting equilibrium wholesale prices in terms of the level of VTT are:

$$
w_{F_{i}}\left(t_{i}\right)=\frac{1}{2}\left(a-t_{i}+u\right) ; \quad w_{i}\left(t_{i}\right)=\frac{1}{2}\left(a-t_{i}-d_{i}+u\right) .
$$


One can easily observe that the wholesale prices increase with the exogenous upstream marginal cost $(u)$ and decrease with the amount of VTT $\left(t_{i}\right)$. Furthermore, one can observe that the wholesale price charged to the LDC's domestic downstream firm decreases with its cost-disadvantage $\left(d_{L D C}\right)$. The latter holds because $U_{L D C}$ faces lower derived input demand from $D_{L D C}$ 's due to the latter's cost-disadvantage. As $D_{L D C}$ 's cost-disadvantage gets more severe, $U_{L D C}$ decreases the wholesale price in order to ensure that $D_{L D C}$ 's input demand does not reduce too much.

In stage two, the MNE chooses how much technology it will transfer upstream. In particular, it solves the following problem:

$$
\underset{t_{i}}{\operatorname{Max}_{i}} \pi_{D_{F i}}=\left[a-q_{F i}\left(t_{i}\right)-q_{i}\left(t_{i}\right)\right] q_{F i}\left(t_{i}\right)-w_{F i}\left(t_{i}\right) q_{F i}\left(t_{i}\right)-\mu_{i} t_{i}^{2} / 2,
$$

where $q_{F i}\left(t_{i}\right)$ and $q_{i}\left(t_{i}\right)$ are obtained after substituting $(7)$ respectively into $q_{F i}\left(w_{F_{i}}, w_{i}\right)$ and $q_{i}\left(w_{F i}, w_{i}\right)$. The equilibrium level of VTT is:

$$
t_{i}^{*}=\frac{a+d_{i}-u}{18 \mu_{i}-1}
$$

We see from (8), that the equilibrium level of technology transferred decreases with $\mu_{i}$. That is, the more costly is technology transfer, the less technology is transferred. This finding is not surprising and it is in line with Blalock and Gertler (2009) who, in their empirical study of FDI in Indonesia, find that domestic firms with highly educated employees are more likely to enjoy higher productivity from FDI. Also from (8), we see that, as the inefficiency of the domestic upstream supplier increases $(u)$, the less technology is transferred vertically. Interestingly though, the opposite holds when the inefficiency of the domestic downstream firm $\left(d_{i}\right)$ increases. Intuitively, this occurs because it is increasingly more beneficial for the MNE to transfer technology when its downstream rival is marginalized, and thus, its own market share increases.

Using (7) and (8), we obtain the equilibrium wholesale prices paid by the MNE and the domestic downstream firm, $w_{F i}^{*}$ and $w_{i}^{*}$ respectively. It is easy to verify that $w_{F L D C}^{*}>$ $w_{L D C}^{*}$. This means that when price discrimination is possible, the upstream monopolist attempts to decrease, instead of increase, the cost asymmetry between the downstream 
firms in the LDC, i.e., it compresses the differences in downstream firms' competitiveness. By favoring the less productive firm, it decreases the allocative efficiency. ${ }^{11}$

In which host country will the MNE transfer more technology?

Proposition 1 There is more vertical technology transfer when the MNE locates its FDI in the $D C$ than when it locates it in the LDC unless $\mu<1.5$ and $d_{L D C}>d_{L D C}^{t}(\mu)$, where $d_{L D C}^{t}(\mu) \equiv 18(a-u)(\mu-1) / 17$, with $\partial d_{L D C}^{t} / \partial \mu>0$ and $\lim _{\mu \rightarrow 1} d_{L D C}^{t}(\mu)=0$.

A MNE has incentives to transfer technology vertically because by technologically upgrading its supplier, it achieves lower input prices (see Corollary 1 below). However, technology transfer is not for free. Proposition 1 informs us that, although VTT is less costly in the DC than in the LDC, a MNE does not always transfer more technology in the DC. When both the efficiency of its domestic downstream firm and the cost of technology transfer are low enough in the LDC, more VTT takes place there than in the DC. This result can be understood as follows. The more inefficient is the domestic downstream rival in the LDC, the higher is the MNE's market share in the LDC. This, in turn, means that the more the MNE will be able to benefit from a decrease in its wholesale price; hence, the higher are its incentives to transfer technology vertically so that the wholesale price decreases. However, if technology transfer in the LDC is relatively costly, less technology will be transferred there even when the LDC's domestic downstream firm's cost disadvantage is large enough. In line with this, Proposition 1 also informs us that it is more likely that more technology will be transferred in the DC rather than in the LDC as the cost of technology transfer in the LDC increases $\left(\partial d_{L D C}^{t} / \partial \mu>0\right)$.

A testable implication arises from the above: We should expect to see more VTT taking place in countries in which their technological gap from the MNE's home country is quite large than in countries where their technological gap from the MNE's home country is relatively small.

Corollary 1 A MNE pays a lower wholesale price when it locates its FDI in the DC than when it locates it in the $L D C$ unless $\mu<1.5$ and $d_{L D C}>d_{L D C}^{t}(\mu)$.

\footnotetext{
${ }^{11}$ A similar result, under trading through wholesale price contracts but without FDI, can be found in DeGraba (1990), Yoshida (2000), and Inderst and Valletti (2009). Inderst and Shaffer (2009) demonstrate that the opposite holds under two-part tariff contracts and price discrimination.
} 
Using the equilibrium expressions for VTT and for the wholesale prices, the equilibrium profits of the domestic upstream firm under FDI equal:

$$
\pi_{U_{i}}^{*}=\frac{18 \mu_{i} d_{i}\left(6 \mu_{i}-1\right)\left[d_{i}-(a-u)\right]+d_{i}^{2}+108 \mu_{i}(a-u)^{2}}{2\left(18 \mu_{i}-1\right)^{2}}
$$

while that of the MNE and the domestic downstream firm are:

$$
\pi_{D_{F i}}^{*}=\frac{\mu_{i}\left(a+d_{i}-u\right)^{2}}{2\left(18 \mu_{i}-1\right)} ; \quad \pi_{D_{i}}^{*}=\frac{\left[d_{i}-12 \mu_{i} d_{i}+6 \mu_{i}(a-u)\right]^{2}}{4\left(18 \mu_{i}-1\right)^{2}} .
$$

\subsection{Location Choice}

We are now in the position to answer the following question: Where will the MNE locate its FDI?

Proposition 2 A MNE prefers to locate its FDI in the DC rather than in the LDC if and only if $d_{L D C}<d_{L D C}^{\pi}(\mu)$, where

$$
d_{L D C}^{\pi}(\mu) \equiv(a-u)\left[\sqrt{\frac{18 \mu-1}{17 \mu}}-1\right]
$$

with $\partial d_{L D C}^{\pi} / \partial \mu>0,0<d_{L D C}^{\pi}(\mu)<\min \left\{d_{L D C}^{t}(\mu), \widehat{d}_{L D C}(\mu)\right\}$, and $\lim _{\mu \rightarrow 1} d_{L D C}^{\pi}(\mu)=0$.

A MNE which operates in a vertically related industry, in contrast to one which operates in a one-tier industry, does not always locate its FDI in the host country where it faces weaker competition. Proposition 2 states that a MNE earns greater profits from entering a DC than from entering a LDC if the technological gap among the two countries is relatively small (i.e., low $d_{L D C}$ ). Intuitively, the downstream market conditions are always in favor of locating in the LDC. This is why, as we saw in the benchmark case, in the absence of an upstream sector, the LDC's domestic downstream firm's cost disadvantage always directs the MNE's FDI towards the LDC. However, when a MNE operates in a vertically related market, the upstream market conditions do not always favor the LDC. More specifically, we know from Corollary 1 that, due to VTT, the MNE obtains the input at better terms, and thus, faces lower marginal cost when it locates in the DC than in the LDC when the latter's cost disadvantage is relative small. This implies that when the LDC's downstream 
firm's cost disadvantage is sufficiently large, the MNE has two reasons to enter into the LDC: In the LDC, it enjoys both weaker downstream competition and lower input prices. When, instead, the LDC's downstream firm's cost disadvantage is relatively small, the MNE is confronted with the following trade off: By entering into the DC, it faces stronger downstream competition, but it enjoys higher upstream production efficiency. When the impact of the upstream market conditions dominates, the MNE locates in the DC. We should note though that this does not always happen: There cases in which although the MNE pays a lower input price in the DC, still it locates in the LDC $\left(d_{L D C}^{\pi}(\mu)<d_{L D C}^{t}(\mu)\right)$ due to its downstream market advantage.

What about the role of $\mu$ ? Proposition 2 informs us that as technology transfer becomes more costly in the LDC ( $\mu$ increases), the MNE is less likely to invest there. In light of the above, the intuition for this is straightforward. The more costly is VTT in the LDC, the less technology will be transferred in the LDC relative to the DC; hence, the less likely is that the upstream market conditions will be in favor of locating in the LDC. In the extreme case in which the two countries do not differ in terms of the downstream cost but only in terms of the technology transfer cost, the MNE always invests in the DC.

We can conclude from the above that the consideration of the potential host countries upstream market conditions is crucial for the analysis of the MNEs' location decisions. Without including the upstream market, we would predict that a MNE always undertakes FDI in the LDC. Whereas, including the upstream market, and thus, considering the vertical structure of the market, we are able to provide a novel explanation for the commonly observed FDI in DCs. In our setting, the choice of the DC over the LDC for the location of FDI is not due to technology sourcing or intellectual property rights arguments already provided by the literature. Instead, it is due to the consideration of the fact that when MNEs choose the location of their FDI, they take into account also their relations with their domestic input suppliers and the respective input prices. Our findings suggest that we should expect to see more often FDI directed towards DCs than towards LDCs by MNEs which source their inputs locally than by MNEs which are vertically integrated. Furthermore, they suggest that in industries in which the technological gap between DCs and LDCs is relatively large, we should expect to see more FDI taking place in LDCs than 
in DCs.

\subsection{Impact of FDI}

Next, we characterize the implications of FDI for its host country. Comparing what happens in host country $i$ under FDI and under autarky (i.e., without FDI), we find the following:

Proposition 3 FDI decreases its host country's wholesale prices and domestic downstream firm's profits and increases its domestic upstream firm's profits, consumers' surplus, and total welfare.

Clearly, the cost-reduction that the domestic upstream firm enjoys, due to VTT, when FDI locates in its home country, allows it to charge lower wholesale prices than in the case of autarky. ${ }^{12}$ This influences, in turn, the impact of FDI on the domestic downstream firm. More specifically, a domestic downstream firm is affected in two separate ways by the MNE's entry: Under FDI, it pays a lower wholesale price, but at the same time its market share declines due to the increased competition from the entering MNE. As Proposition 3 states, the effect of the loss of the monopoly position is more severe, and the domestic downstream firm is worse off when FDI is undertaken in its home country. The opposite is true for the domestic upstream firm upon which FDI confers two advantages: First, under FDI, the domestic upstream firm's efficiency is enhanced as a result of VTT. And second, under FDI, the demand faced by the domestic upstream firm increases because of greater downstream competition due to the entry of the MNE (increase in backward linkages). Actually, in the case of the LDC, the boost in the derived demand is also due to the cost-advantage that the entering MNE enjoys relative to the domestic downstream customer. Blalock and Gertler (2008) provide empirical support to the positive impact of downstream FDI on the output and profits of the domestic upstream firms.

FDI results into an increase in its host country's downstream competition, as well as into an increase in its downstream efficiency because of the lower input prices. Both of

\footnotetext{
${ }^{12}$ We should note that in our setting, if VTT was absent, the wholesale price(s) would be the same under FDI and autarky. Thus, the existence of the upstream market would not affect the location choice of FDI.
} 
these effects explain the subsequent rise in the host country's consumers' surplus under FDI. What about though the FDI's impact on the host country's total welfare? As was already noted, the MNE's entry increases the consumers' surplus and the upstream producer's surplus, but it decreases the downstream producer's surplus. Proposition 3 asserts that the net impact of FDI is always positive. Therefore, FDI should always be welcomed by a host country. This holds independently of whether the host country is more or less developed. On the basis of this result, we conclude that host economy policy makers should, at a minimum, not raise barriers to FDI. In fact, in cases where there is potential for MNE to source supplies from domestic suppliers, policy makers should consider providing incentives to encourage FDI. Having said that, one might wonder whether a DC or a LDC should encourage FDI more. The following Proposition addresses this issue.

Proposition $4 A D C$ benefits more from FDI than a LDC in terms of total welfare if and only if $d_{L D C}<d_{L D C}^{W}(\mu)$, where

$d_{L D C}^{W}(\mu) \equiv \frac{(a-u)\left[\sqrt{(1-18 \mu)^{2}[68953+12 \mu(39315 \mu-21179)]}-17[7+12 \mu(45 \mu-1)]\right]}{51[7+4 \mu(63 \mu-23)]}$,

with $\partial d_{L D C}^{W} / \partial \mu>0,0<d_{L D C}^{W}(\mu)<\widehat{d}_{L D C}(\mu)$, and $\lim _{\mu \rightarrow 1} d_{L D C}^{\pi}(\mu)=0$.

The welfare increasing effect of FDI is more pronounced in a DC only as long as the technological gap among the two countries is small enough. In contrast to conventional explanations, this holds not because of the unintentional horizontal technology transfer from the MNE to the inefficient domestic firms of the LDC. Instead, it holds because of the intentional technology transfer from the MNE to the LDC's domestic upstream firm. More specifically, as we saw in Proposition 1, when the LDC's domestic downstream firm's cost disadvantage is sufficiently high, more technology is transferred when FDI locates in a LDC. As a result, the efficiency of the domestic upstream firm, and in turn, of the domestic downstream firms (due to the subsequent lower wholesale prices) increases more in the LDC then, leading in turn, to a higher increase in both consumers' and producers' surplus. 


\section{Extensions}

In this Section, we consider various extensions of our main model. Doing so, we examine the robustness of our results, as well as we obtain some new insights. ${ }^{13}$

\subsection{Firm/Input-specific VTT}

In the model studied so far, the technology transferred vertically was reducing the production cost of the input used by both the foreign and the domestic downstream firms. As a result, not only the MNE but also the domestic downstream firm was benefiting by VTT. In other words, in our main model, the domestic downstream firm was (indirectly) free-riding on the VTT. We now consider a situation where free-riding is absent. This could be the case because the inputs are firm-specific, and in turn, VTT is firm-specific. More specifically, we make the following modification in our model: We assume that when the MNE invests in host country $i$, then $U_{i}$ 's marginal cost of producing the input for $D_{F i}$ is $u-t_{i}$, while that of producing the input for $D_{i}$ is $u$. Under this specification, we need to modify Assumption 1 and assume instead that $d_{L D C}<(a-u) \frac{3 \mu-1}{6 \mu-1}$.

Obtaining the equilibrium level of VTT and comparing it with the respective one in our main model, we conclude that the (indirect) free-riding of the domestic downstream firm has a negative effect on VTT. This is quite intuitive: The MNE has less incentives to transfer technology when its rival will also benefit from the transfer than when it will not.

In contrast to what it happens in the presence of free-riding, we find that in its absence the MNE always transfers more technology in the DC rather than in the LDC. Why is that? The free-riding of the DC's domestic downstream firm on the MNE's VTT is more harmful for the MNE than the respective free-riding of the LDC's domestic downstream firm mainly because the former firm is a stronger competitor than the latter. This, in turn, means that the disappearance of free-riding results into a higher relative increase of VTT in the DC.

Still, similarly to our main model, we find that the MNE locates its FDI in the DC if and only if the cost disadvantage of the LDC's domestic downstream firm is sufficiently small.

\footnotetext{
${ }^{13}$ The detailed analysis of the extensions is available from the author upon request.
} 
In particular, this happens now when $d_{L D C}<(a-u)\left[\frac{\sqrt{\mu(9 \mu-2)}}{\mu \sqrt{7}}-1\right]$. The implications of FDI on its host country are also similar to the ones obtained with our main model. The only exception is that now FDI leaves the wholesale price charged to the domestic downstream firm unchanged.

\subsection{Quality Enhancing VTT}

In our main model, we assumed that VTT leads to a reduction in the upstream production cost. Alternatively, VTT could lead to an increase in the quality of the upstream input, and thus, to an increase in the final product's quality. Would our results change then? In order to answer this, we consider a modification of our model, in which $U_{i}$ 's marginal cost is always $u$ and the demand in the host country in which the FDI takes place is $p_{i}=a+t_{i}-q_{f i}-q_{i}$, i.e., VTT results into an increase in the demand of the final product. The rest of our model remains unchanged.

Under quality-enhancing VTT, we confirm all our main findings regarding the comparison of VTT in the two host countries, as well as regarding the location choice of FDI and its impact on the host country. The only thing that changes is that now FDI leads to an increase, instead of a decrease, in the wholesale price of its host country. This occurs because, when the quality of the input increases (due to VTT) while its production cost remains the same, the upstream supplier charges a higher price as a reaction to the fact that it faces higher demand.

\subsection{Absorptive Capacity}

We assumed so far that VTT is more costly in the LDC than in the DC because in the former country either the employees are less trained or a different technology is used than the one in the DC. One could argue though that the type of technology used and/or the training and educational background of the personnel would make the two host countries differ not in terms of the cost of VTT, but in terms, instead, of their absorptive capacity, i.e., in terms of their capacity to assimilate and apply the technology transferred, and thus, to exploit the technology transferred.

In order to consider what would happen then, we alter our model. We set $\mu_{L D C}=1$ and assume that the upstream marginal cost in the host country is given by $u-k_{i} t_{i}$, 
where $k_{D C}=1$ and $k_{L D C}=k$, with $0 \leq k<1$. Clearly, $k_{i}$ is a measure of host country $i$ 's absorptive capacity, with a higher $k_{i}$ corresponding to higher capacity. Moreover, we modify accordingly Assumption 1, and assume now that $d_{L D C}<\frac{12}{24-k^{2}}(a-u)$. Doing so, we conclude that the lower is $k$, the less VTT takes place in the FDI's host country. This is expected since when the upstream supplier is unable to exploit the transferred technology, the foreign downstream firm has weaker incentives to incur the cost of VTT. Once again we find that more VTT takes place in the DC and FDI locates there only when the technology gap is sufficiently small. With regard to the implications of FDI on its host country, we confirm all of them.

\subsection{No Price Discrimination}

Throughout our analysis, we assumed that the local upstream supplier can price discriminate among the foreign and the domestic downstream firms. What would happen if price discrimination was not allowed by the host country's government?

Modifying Assumption $1\left(d_{L D C}<\frac{6 \mu(a-u)}{21 \mu-2}\right)$, and obtaining the equilibrium level of VTT under no price discrimination, we find that in the DC it is equal to the respective one under price discrimination. This is so because in the DC the domestic and the foreign downstream firms are symmetric. Instead, in the LDC, where the foreign downstream firm is more efficient than the domestic downstream firm, the wholesale prices charged to the two firms differ and more VTT takes place in the absence than in the presence of price discrimination. The latter occurs because in the LDC under no price discrimination, the common wholesale price charged to both the foreign and the domestic downstream firms is negatively affected by the latter's marginal cost. This means that, taking the level of VTT as given, the MNE pays a lower wholesale price in the LDC under no price discrimination than under price discrimination. In turn, the MNE's incentives for VTT in the LDC are stronger under no price discrimination. This finding suggests that the LDC's government should prohibit price discrimination. Such a prohibition would result into more technology being transferred, lower input prices and subsequently higher consumers' surplus and total welfare.

Similarly to the case of price discrimination, we find that more VTT takes place in the DC unless $\mu$ is sufficiently low and $d_{L D C}$ sufficiently high. Furthermore, our findings 
regarding the location choice of FDI and its implications are qualitatively similar to the ones in our main model.

\subsection{Upstream Cost-Disadvantage}

Suppose now that the two host countries do not differ in terms of the cost of VTT, but that the LDC, besides its downstream cost disadvantage, has also an upstream cost disadvantage. That is, suppose that $\mu_{L D C}=1$ and that the initial upstream marginal cost in host country $i$ is $u_{i}$, with $u_{L D C}>u_{D C}$.

We find that the higher is $u_{i}$, the lower is $t_{i}$. This confirms the empirical finding of Jabbour and Mucchielli (2007) according to which only highly productive domestic upstream firms benefit (become more productive) due to downstream foreign entry. However, at the same time, we find that, as in our main model, the higher is $d_{i}$, the higher is $t_{i}$. Due to the two opposite effects, VTT takes place in the DC if and only if $d_{L D C}<u_{L D C}-u_{D C}$. In other words, the MNE undertakes more VTT in the DC as long as the LDC's downstream cost disadvantage is smaller than its upstream cost disadvantage, and thus, the upstream market conditions influence more its incentives. When more VTT takes place in the DC, the MNE locates its FDI there. That is, in this situation the level of VTT dictates the location decision.

\subsection{Two-part Tariffs}

We extend now our analysis to the case in which vertical trading is conducted through two-part tariff contracts, i.e., through contracts which consist of both a wholesale price per unit of input, $w_{s}$, and a fixed fee-transfer, $A_{s}$, with $s=F_{i}, i$. For the analysis to be non-trivial, we need to incorporate bargaining over two-part tariffs. Otherwise, under two-part tariffs, when the domestic upstream monopolist makes its take-it-or-leaveit contract offer(s) in stage three, it will obtain through the fixed fee all the downstream gross profits. Given this, the foreign downstream firm will make negative profits if it transfers technology vertically in stage two. Thus, a necessary condition for VTT is that the downstream firms possess some bargaining power during their negotiations with the upstream monopolist. In our modified model, we invoke the Nash bargaining solution and assume that the bargaining power of $U_{i}$ is given by $\beta$, with $0<\beta<1$, while that of each 
downstream firm is given by $1-\beta$.

Assuming that when the MNE undertakes FDI in host country $i, U_{i}$ bargains simultaneously and separately with $D_{F i}$ and $D_{i}$ over $\left(w_{F_{i}}, A_{F_{i}}\right)$ and $\left(w_{i}, A_{i}\right)$ respectively, and modifying Assumption 1 as needed, we confirm qualitatively all our main results. ${ }^{14}$ Therefore, we conclude that they are, to a large extent, independent of whether trading takes place through linear or non-linear contracts.

\section{Concluding Remarks}

We have endogenized the location of FDI when a MNE has to choose among investing in a developed or a less developed host country. We have done so considering a vertically related market and endogenizing VTT.

We have shown that the MNE does not always transfer vertically more technology in the host country where the transfer cost is lower. In fact, more VTT takes place in the LDC than in the DC when in the LDC, technology transfer is not too costly and the cost disadvantage is sufficiently large. Furthermore, we have shown that the technological gap between the two host countries plays a pivotal role in determining the location of FDI. While in a one-tier industry, the MNE will always locate its FDI in the LDC where it faces weaker competition, in a vertically related industry, it will locate it in the DC only when the technological gap is sufficiently small. This is so because more technology is transferred in the DC then, and as a result, the input price is lower.

The potential host countries, independently of whether they are more or less developed, should welcome FDI. The entry of the MNE in their domestic market results into an increase in downstream competition and downstream efficiency, hurting, in turn, the domestic downstream firm, but benefiting the domestic upstream supplier and the consumers, and enhancing the total welfare.

Summing up, in this paper, we have provided a novel explanation for the well-established empirical observation that FDI mainly flows between technologically advanced countries. We have pointed out that the vertical structure of the market, and the upstream market

\footnotetext{
${ }^{14}$ For a similar modeling approach of bargaining over vertical contracts and a more detailed description of it see e.g., McAfee and Schwartz (1994, 1995), and Milliou and Petrakis (2007).
} 
conditions can crucially affect the location decision of FDI, and thus, that their role should not be ignored in the analysis of such decisions.

We have performed our analysis using a simple framework, but we have demonstrated that our main findings are robust to various modifications of our modeling assumptions. Still, in our future work we plan to further expand our framework. In particular, given that in the last few years the percentage of FDI that takes place through cross-border mergers and acquisitions, instead of through Greenfield Investment, has increased significantly, we plan to analyze the location choice of FDI when FDI corresponds to an acquisition of a domestic firm. Furthermore, we plan to consider a setting with various MNEs and examine how their interaction might influence their location decisions.

\section{Appendix}

Proof of Proposition 1: From (8), we set $M_{t}\left(\mu, d_{L D C}\right) \equiv t_{D C}^{*}-t_{L D C}^{*}=0$ and solving for $d_{L D C}$, we find $d_{L D C}^{t}(\mu) \equiv 18(a-u)(\mu-1) / 17$, with $\partial d_{L D C}^{t} / \partial \mu>0, d_{L D C}^{t}(\mu)>0$ and $\lim _{\mu \rightarrow 1} d_{L D C}^{t}(\mu)=0$. Moreover, we find that $\lim _{d_{L D C} \rightarrow 0} M_{t}\left(\mu, d_{L D C}\right)>0, M_{t}\left(\mu, d_{L D C}\right)>$ 0 when $d_{L D C}<d_{L D C}^{t}(\mu)$ and $M_{t}\left(\mu, d_{L D C}\right)<0$ when $d_{L D C}>d_{L D C}^{t}(\mu)$. We note though that $d_{L D C}^{t}(\mu)>\widehat{d}_{L D C}(\mu)$ if and only if $\mu>1.5$. Thus, given Assumption 1 , when $\mu>1.5$, we have $t_{D C}^{*}>t_{L D C}^{*}$. Instead, when $\mu<1.5$, we have $t_{D C}^{*}>t_{L D C}^{*}$ if and only if $d_{L D C}<d_{L D C}^{t}(\mu)$.

Proof of Corollary 1: From (7), we know that $w_{F D C}\left(t_{D C}^{*}\right)-w_{F L D C}\left(t_{L D C}^{*}\right)=t_{L D C}^{*}-t_{D C}^{*}$. The rest of the proof is the same as the proof of Proposition 1.

Proof of Proposition 2: From (10), we set $M_{\pi}\left(\mu, d_{L D C}\right) \equiv \pi_{D_{F D C}}^{*}-\pi_{D_{F L D C}}^{*}=0$ and solving for $d_{L D C}$, we find $d_{L D C}^{\pi}(\mu) \equiv(a-u)\left[\sqrt{\frac{18 \mu-1}{17 \mu}}-1\right]$, with $\partial d_{L D C}^{\pi} / \partial \mu>0,0<$ $d_{L D C}^{\pi}(\mu)<\min \left\{d_{L D C}^{t}(\mu), \widehat{d}_{L D C}(\mu)\right\}$, and $\lim _{\mu \rightarrow 1} d_{L D C}^{\pi}(\mu)=0$. Moreover, we find that $M_{\pi}\left(\mu, d_{L D C}\right)>0$ when $d_{L D C}<d_{L D C}^{\pi}(\mu)$ and $M_{\pi}\left(\mu, d_{L D C}\right)<0$ when $d_{L D C}>d_{L D C}^{\pi}(\mu)$. Therefore, $\pi_{D_{F D C}}^{*}>\pi_{D_{F L D C}}^{*}$ if and only if $d_{L D C}<d_{L D C}^{\pi}(\mu)$.

Proof of Proposition 3: Under autarky in host country $i$, the equilibrium quantity, whole- 
sale price, and profits are:

$q_{i}^{A}=\frac{1}{4}\left(a-d_{i}-u\right) ; \quad w_{i}^{A}=\frac{1}{2}\left(a-d_{i}-u\right) ; \quad \pi_{D_{i}}^{A}=\frac{1}{16}\left(a-d_{i}-u\right)^{2} ; \quad \pi_{U_{i}}^{A}=\frac{1}{8}\left(a-d_{i}-u\right)^{2}$.

We take the difference $w_{i}^{*}-w_{i}^{A}=\frac{a+d_{i}-u}{2-36 \mu_{i}}$. We note that it is always negative. Thus, the wholesale price is lower under FDI than under autarky.

We set $M_{A D}\left(\mu_{i}, d_{i}\right) \equiv \pi_{D_{i}}^{*}-\pi_{D_{i}}^{A}=0$ and solving for $d_{i}$, we find $d_{i}^{A D}\left(\mu_{i}\right) \equiv \frac{(a-u)\left(-1+30 \mu_{i}\right)}{-3+42 \mu_{i}}$. Moreover, we find that $M_{A D}\left(\mu_{i}, d_{i}\right)>0$ if and only if $d_{i}>d_{i}^{A D}\left(\mu_{i}\right)$. We note that $d_{L D C}^{A D}(\mu)>\widehat{d}_{L D C}(\mu)$. Thus, given Assumption 1, we can never have $\pi_{D_{L D C}}^{*}-\pi_{D_{L D C}}^{A}>0$. Similarly since $d_{D C}=0<d_{D C}^{A D}(1)$, we can never have $\pi_{D_{D C}}^{*}-\pi_{D_{D C}}^{A}>0$.

We take the difference $\pi_{U_{i}}^{*}-\pi_{U_{i}}^{A}$ and we note that it is always positive. Therefore, the profits of the domestic upstream firm are always higher under FDI than under autarky.

Consumer surplus in host country $i$, under FDI is given by $C S_{i}^{*}=q_{F i}\left(w_{F i}^{*}, w_{i}^{*}\right)^{2}+$ $q_{i}\left(w_{F i}^{*}, w_{i}^{*}\right)^{2}$, while under autarky it is given by $C S_{i}^{A}=\frac{1}{2} q_{i}^{A}$. We set $M_{A C S}\left(\mu_{i}, d_{i}\right) \equiv$ $C S_{i}^{*}-C S_{i}^{A}=0$ and solving for $d_{i}$, we find $d_{i}^{A C S}\left(\mu_{i}\right) \equiv \frac{(a-u)\left(-1+42 \mu_{i}\right)}{30 \mu_{i}-3}$. Moreover, we find that $M_{A C S}\left(\mu_{i}, d_{i}\right)>0$ if and only if $d_{i}<d_{i}^{A C S}\left(\mu_{i}\right)$. We know that $d_{D C}=0<d_{D C}^{A C S}(1)$ and we note that $d_{L D C}^{A C S}(\mu)>\widehat{d}_{L D C}(\mu)$. Thus, given Assumption 1, we always have $C S_{i}^{*}-C S_{i}^{A}>0$.

Total welfare in host country $i$, under FDI is given by $T W_{i}^{*}=C S_{i}^{*}+\pi_{U_{i}}^{*}+\pi_{D_{i}}^{*}$, while under autarky it is given by $T W_{i}^{A}=C S_{i}^{A}+\pi_{U_{i}}^{A}+\pi_{D_{i}}^{A}$. We take the difference $T W_{i}^{*}-T W_{i}^{A}$ and we note that it is always positive. Hence, FDI has a positive effect on its host country's total welfare.

Proof of Proposition 4: We set $M_{A T W}\left(\mu, d_{L D C}\right) \equiv T W_{D C}^{*}-T W_{D C}^{A}-\left(T W_{L D C}^{*}-T W_{L D C}^{A}\right)$ and solving for $d_{L D C}$, we find $d_{L D C}^{W}(\mu)$ with $\partial d_{L D C}^{W} / \partial \mu>0,0<d_{L D C}^{W}(\mu)<\widehat{d}_{L D C}(\mu)$, and $\lim _{\mu \rightarrow 1} d_{L D C}^{\pi}(\mu)=0 d_{L D C}^{A T W}(\mu)$. Moreover, we find that $M_{A T W}\left(\mu, d_{L D C}\right)>0$ if and only if $d_{L D C}<d_{L D C}^{W}(\mu)$.

\section{References}

Balsvik, R., 2010, "Multinationals' mode of entry with presence of upstream spillovers," Economica 77, 334-351. 
Barros, P., Cabral, L., 2000, "Competing for foreign direct investment," Review of International Economics 8, 360-371.

Bjorvatn, K., Erckel, C., 2006, "Technology sourcing and strategic foreign direct investment," Review of International Economics 14, 600-614.

Blalock, G., Gertler, P., 2008, "Welfare gains from foreign direct investment through technology transfer to local suppliers," Journal of International Economics 74, 402-421.

Blalock, G., Gertler, P., 2009, "How firm capabilities affect who benefits from foreign technology," Journal of Development Economics 90, 192-199.

Carluccio, J., Fally, T., 2011, "Foreign entry and spillovers with technological incompatibilities in the supply chain," unpublished manuscript, University of Colorado at Boulder.

Chou, S. J.-H., 2011, "Differentiated products, vertical related markets, and optimal export policy," Review of International Economics 19, 449-458.

DeGraba, P., 1990, "Input-market price discrimination and the choice of technology," American Economic Review 80, 1246-53.

Fumagalli, C., 2003, "On the welfare effects of competition for foreign direct investment," European Economic Review 47, 963-983.

Inderst, R., Valletti, T., 2009, "Price discrimination in input markets," Rand Journal of Economics 40, 1-19.

Inderst, R., Shaffer, G., 2009, "Market power, price discrimination, and allocative efficiency in intermediate-goods market," Rand Journal of Economics 40, 658-672.

Ishikawa, J., Spencer, B., 1999, "Rent-shifting export subsidies with an imported intermediate product," Journal of International Economics 48, 199-232.

Goh, A.-T., 2005, "Knowledge diffusion, input supplier's technological effort and technology transfer via vertical relationships," Journal of International Economics 66, 527-540.

Jabbour, L., Mucchielli, J. L., 2007, "Technology transfer through vertical linkages: The case of the Spanish manufacturing industry," Journal of Applied Economics, 10, 115136.

Javorcik, B., 2004, "Does foreign direct investment increase the productivity of domestic firms? In search of spillovers through backward linkages," American Economic Review 
94, 605-627.

Kurata, H., Ohkawa, T., Okamura, M., 2011, "Market size and firm location in a service industry," Review of International Economics 19, 1-14.

Lall, S., 1980, "Vertical inter-firm linkages in LDCs: An empirical study," Oxford Bulletin of Economics and Statistics 42, 203-226.

Lileeva, A., 2010, "The benefits to domestically owned plants from inward direct investment: The role of vertical linkages," Canadian Journal of Economics 43, 574-603.

Lin, P., Saggi, K., 2007, "Multinational firms, exclusivity, and backward linkages," Journal of International Economics 71, 206-220.

Lin, P., Saggi, K., 2011, "FDI in a two-tier oligopoly: Coordination, vertical integration, and welfare," International Economic Review 52, 1271-1290.

Ma, J. (2011). "Market size, local sourcing and policy competition for foreign direct investment," Review of International Economics, forthcoming.

Markusen, J. R., 1995, "The boundaries of multinational enterprises and the theory of international trade," Journal of Economic Perspectives 9, 169-189.

Markusen, J. R., Venables, A., 1999, "Foreign direct investment as a catalyst for industrial development," European Economic Review 43, 335-356.

McAfee, P. , Schwartz, M., 1994, "Opportunism in multilateral vertical contracting: Nondiscrimination, exclusivity, and uniformity," American Economic Review 84, 210-230.

McAfee, P., Schwartz, M., 1995, "The non-existence of pairwise-proof equilibrium," Economics Letters 49, 251-259.

Milliou, C., Petrakis, E., 2007, "Upstream horizontal mergers, vertical contracts, and bargaining," International Journal of Industrial Organization 25, 963-987.

Motta, M., Ronde, T., 1999, "Multinationals without advantages," Scandinavian Journal of Economics 101, 617-630.

OECD, 2002, Foreign direct investment for development, OECD, Paris, France.

Pack, H., Saggi, K., 2001, "Vertical technology transfer via international outsourcing," Journal of Development Economics 65, 389-415.

Qiu, L., Wang, S., 2011, "FDI policy, Greenfield Investment and cross-border mergers," Review of International Economics 19, 836-851. 
Rodriguez-Clare, A., 1996, "Multinationals, linkages, and economic development," American Economic Review 86, 852-873.

UNCTAD, 2007, World investment report 2007, United Nations, New York and Geneva. UNCTAD, 2008, World investment report 2008, United Nations, New York and Geneva. UNCTAD, 2012, World investment report 2012, United Nations, New York and Geneva. Yoshida, Y., 2000, "Third-degree price discrimination in input markets: Output and welfare," American Economic Review 90, 240-46. 